\title{
Cerebral achromatopsia as a presentation of Trousseau's syndrome
}

\author{
Richard W Orrell, Merle James-Galton, John M Stevens, Martin N Rossor
}

\begin{abstract}
Summary
A 67-year-old man developed a sudden onset of achromatopsia. Magnetic resonance imaging showed occipital lobe infarction. Repeated episodes of neurological deficit referable to the posterior circulation initially suggested an embolic source, but subsequently proved to be due to a coagulopathy related to a carcinoma of the bladder. This has implications for the management of patients presenting with achromatopsia, and progressive or recurrent neurological episodes, and in particular the use of anticoagulation in this situation.
\end{abstract}

Keywords: cerebral achromatopsia, Trousseau's syndrome, bladder carcinoma, disseminated intravascular coagulation

\section{Introduction}

'Cerebral achromatopsia is a syndrome in which the patient loses the ability to see colours after cortical damage. This loss may be complete or partial, and it may or may not be accompanied by other visual defects' ${ }^{1,2}$ We describe a case of this unusual but readily recognisable clinical syndrome, and its association with a paraneoplastic coagulopathy.

\section{Case report}

St Mary's Hospital, Praed Street, London, UK

Department of

Neurology

RW Orrell

MN Rossor

Department of

Neuroradiology

JM Stevens

Department of

Clinical

Neuropsychology, The

National Hospital,

Queen Square,

London, UK

$M$ James-Galton

Correspondence to

Dr Richard W Orrell,

Academic Unit of

Neuroscience, Charing Cross

Hospital, Fulham Palace

Road, London W6 8RF, UK

Accepted 11 August 1994
A 67-year-old man was travelling as a front seat passenger in a car when he experienced a sudden brilliant flash of white throughout his vision, followed by a kaleidoscope effect, with criss-cross lines and bright colours. The experience lasted about 20 seconds, and he was left with some fogginess of vision, and was only able to see images in black and white. Three weeks previously he had experienced an episode of weakness in the right hand, lasting for two days, but otherwise had no previous neurological symptoms. Over a period of two weeks there was some improvement in his vision, but persistence of the loss of colour vision.

Eighteen months previously he had presented with haematuria. Cystoscopy demonstrated a multifocal transitional cell carcinoma on the left wall of the bladder which was in the early invasive stage. This was being controlled by repeated cystoscopy and fulguration. He had ischaemic heart disease, with occasional angina, had coronary artery by-pass grafting four years previously, and had been taking $300 \mathrm{mg}$ aspirin daily.

On examination he appeared well, with a regular pulse, blood pressure $160 / 100 \mathrm{mmHg}$ normal heart sounds, and no carotid bruits. Neurological examination was normal, but for absent colour vision and a partial right hemianopia. Visual acuity was $6 / 18$ bilaterally.

Two weeks after the onset of visual disturbance he developed a sudden onset of upper motor neurone weakness in the right arm and face, with reduced sensation in the right arm following a bout of heavy coughing. Investigation at this time demonstrated normal ful blood count, erythrocyte sedimentation rate, prothrombin time, serum urea and electrolytes, and glucose. Treponemal serology was negative. Chest radiograph was normal. Computed tomographic (CT) scan of the brain showed an area of presumed recent infarction involving the left occipital lobe and posterior part of the temporal lobe. Magnetic resonance (MR) scan the next day showed bilateral occipital lobe infarction, mainly below the calcarine fissure (see figures). MR angiography showed the posterior circulation to be normal, with no evidence of basilar artery thrombosis. Doppler examination of the carotid arteries showed a $30 \%$ internal carotid stenosis on the right, and $55 \%$ on the left. There was no clinical or electrocardiographic evidence of an arrhythmia, and an echocardiogram showed no evidence of a cardiac source of emboli.

\section{NEUROPSYCHOLOGICAL ASSESSMENT}

A detailed neuropsychological assessment was carried out at the time of the original visual deficit. On the Wechsler Adult Intelligence Scale (Revised) he obtained a verbal IQ of $128 .^{3}$ There was no evidence of generalised intellectual impairment. Recognition memory for verbal material was excellent, he scored in the superior range on the Warrington Recognition Memory for words. ${ }^{4}$

Test of primary visual function were performed. Reading acuity on the Ffookes symbols test was $6 / 18$. Shape discrimination was within normal limits. ${ }^{5}$ Shape detection on the VOSP (Visual Object and Space Perception) figure-ground was unimpaired. ${ }^{6}$ Colour discrimination was severely impaired. $\mathrm{He}$ was unable to pick out any numbers on the Ishihara test. He had great difficulty on the Farnsworth 100 -Hue test, error score $784 .^{7,8}$ There was no evidence of visual disorientation; he was able to 


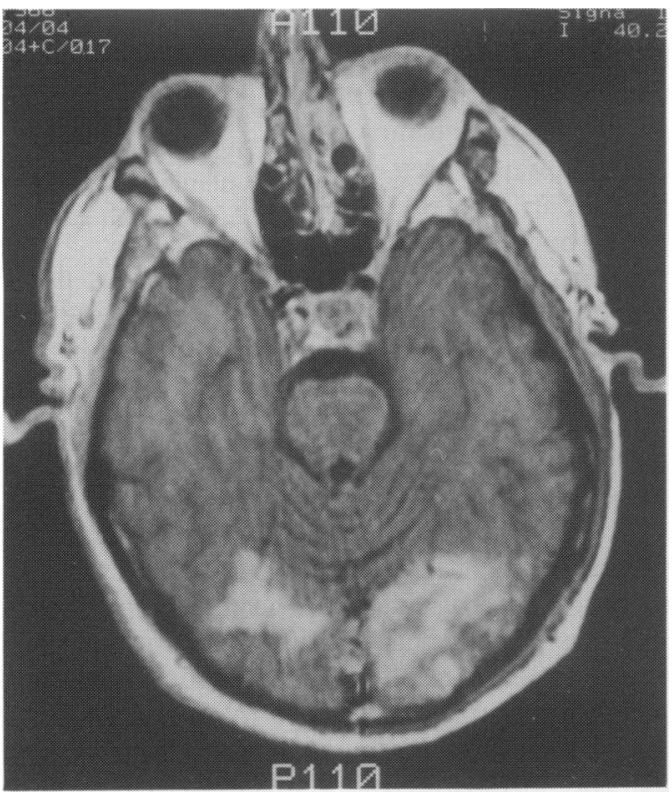

Figure 1 MRI, 1.5 Tesla, with Gadolinium enhancement, showing features of bilateral occipital lobe infarction, more marked on the left

count scattered dots accurately, missing only those which fell within his visual field defect.

Tests of higher visual processing from the VOSP $^{6}$ were performed. He was completely unable to see any form of a letter on the Incomplete Letter task. His performance on the Silhouettes test was very poor (4/30). On the Progressive Silhouettes test he was slow to identify the objects even when complete. $\mathrm{He}$ also made errors of identification of simple line drawings of objects. He showed some degree of prosopagnosias, being able to identify only $1 / 12$ Famous Faces and he complained of difficulty in recognising people.

The interpretation of his neuropsychological assessment is that the only elements of cortical blindness present were a severe achromatopsia and a mild impairment of acuity. In addition he had an aperceptive agnosia. The degree of impairment of his primary visual processing was insufficient to account for his poor performance on tests of visual object processing.

\section{PROGRESS}

In view of the recurrent episodes of neurological deficit, which were felt to be possibly embolic, he was started on an infusion of heparin at 10000 units over 24 hours, with caution because of the haemorrhagic nature of the infarct, and his previous haematuria. The right arm weakness resolved over three days, with a residual mild right facial weakness. $\mathrm{He}$ was commenced on warfarin anticoagulation with careful control.

Two weeks later, having developed mild haematuria and having discontinued the warfarin himself, he was found wandering at night, aphasic and agitated. He had a left upper motor facial weakness, and a progressive left hemiplegia. He had complete cortical blindness, with small pupils, absent gag reflex, and brisk jaw jerk. CT scan at this stage showed extensive bilateral accipital infarction. He was again commenced on a heparin infusion, and over a

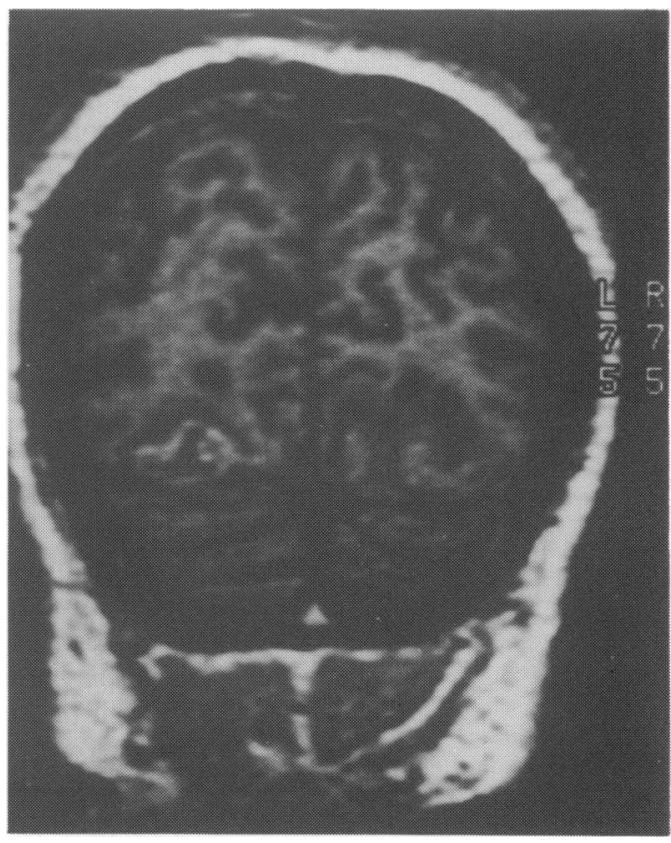

Figure 2 MRI, coronal section of the brain, showing features of bilateral occipital lobe infarction, mainly below the calcarine fissure

period of weeks had some recovery of vision in the left homonymous fields, but remained drowsy, and the heparin was discontinued.

Within two weeks he developed a deep vein thrombosis of the right leg, with gangrenous areas in the toes, and as there was some recovery in his conscious level, heparin was recommenced. Within three months of the initial presentation of visual disturbance he developed significant haematuria, with further evidence of disseminated intravascular coagulation (DIC). Over a period of one week the coagulopathy progressed. This failed to respond to treatment with platelets and fresh frozen plasma and he died peacefully.

Post-mortem examination showed the cause of death to be a pulmonary embolus, with a thrombosed right external iliac vein. There was a stage 4 bladder carcinoma, invading through the bladder wall into the perivesical fat, with a right hydronephrosis and hydroureter. Histology showed an ulcerated poorly differentiated transitional cell carcinoma extending into the perivesicular fat, and lymphatic channel invasion. There was no evidence of metastatic spread. On examining the brain, there were bilateral basal occipital infarcts and bilateral parietal infarcts, all being recent, with signs of colliquative necrosis. Additional infarcts were present in the kidney and spleen, with gangrenous infarction of the right forefoot and toes of the left foot. There was no evidence of an embolic source in the heart or great vessels.

\section{Discussion}

Cerebral achromatopsia has been recognised for many years, with debate over the existence of a specific cortical colour centre. Clinical evidence links the anterior inferior part of the occipital lobe with colour perception in man. Bilateral lesions at this site may cause achroma- 
topsia with preservation of primary visual function. ${ }^{9} \mathrm{~A}$ unilateral lesion will cause hemiachromatopsia. Animal studies, and more recently functional positron emission tomography studies in man, ${ }^{10}$ have shown an area in the lingual and fusiform gyri of man, equivalent to area V4 in the macaque monkey, which appears to function as a centre for colour vision. ${ }^{1}$ More recently, further experimental evidence in the monkey has cast doubt on area V4 being the centre for cortical registration of colour. ${ }^{11}$ Monkeys appear to show the opposite pattern of deficit to humans, with preserved colour discrimination, but impairment of shape discrimination.

Cerebral achromatopsia must be distinguished from other syndromes of impaired colour vision (see box). The description by the patient we report, of the world appearing to be in black and white ('as if watching a black and white television') is typical. The Farnsworth 100-Hue Test $^{7,8}$ assesses the ordering of chromatically graded coloured discs, and is characteristically abnormal in achromatopsia. The assessment of central achromatopsia can be especially difficult when the deficit is limited to a quadrant or hemifield, as it may spare the regions near fixation. ${ }^{12}$

Most cases of cerebral achromatopsia are due to cerebral infarction caused by cerebrovascular disease or embolic phenomena, ${ }^{9}$ and are bilateral, although some cases of homonymous hemiachromatopsia have been reported. ${ }^{13-18}$ Cerebral achromatopsia has also been reported as a rare manifestation of migraine. ${ }^{19}$ Fine emboli occluding the penetrating branches of the calcarine artery at its termination will cause appropriate infarction, whilst larger emboli, and basilar artery occlusion, lead to preservation of the colour centre of the visual cortex as the blood supply is preserved by superficial branches of the posterior and middle cerebral arteries in this area. ${ }^{20} \mathrm{MR}$ angiography would appear to be the investigation of choice.

The association of thrombosis and cancer is well recognised, although the precise mechanisms remain uncertain. Arnand Trousseau first

1 Zeki S. A century of cerebral achromatopsia. Brain 1990; 113: $1721-77$.

2 Plant GT. Disorders of colour vision in diseases of the nervous system. In: Foster D, ed. Inherited and acquired colour vision deficiencies: fundamental aspects and clinical studies. Vision and visual dysfunction. Basingstoke: Macmillan Press, 1991; vol 7, pp 173-98.

3 Wechsler D. Wechsler Adult Intelligence Scale-Revised. New York: Psychological Corporation, 1981.

4 Warrington EK. Recognition memory test. Windsor: NFER Nelson, 1984

5 Efron R. What is perception? In: Cohen RS, Wartofsky MW, eds. Boston studies in the philosophy of science. Dordrecht: D Reidel, 1968, vol 4, pp 137-73.

6 Warrington EK, James M. The visual object and space perception battery. Bury St Edmunds: Thames Valley Test perception

7 Farnsworth D. The Farnsworth-Munsell 100-hue and dichotomous test of colour vision. F Opt Soc Am 1943; 33: 568-78.

8 Farnsworth

Farnsworth D. The Farnsworth-Munsell 100-hue test manual (revised edition). Baltimore: The Minsell Color Co, 1957. Meadows JC. Disturbed perception of colours associate

10 with localized cerebral lesions. Brain 1974; 97: 615-32. cerebral cortex of man. Nature 1989; 340: 386-9.

11 Heywood CA, Gadotti A, Cowey A. Cortical area V4 and its role in the perception of color. $\mathcal{F}$ Neurosci 1992;12: 4056-65.

12 Rizzo M, Smith V, Pokorny J, Damasio AR. Color perception profiles in central achromatopsia. Neurology 1993; 43: 995-1001.

13 Albert ML, Reches A, Silverberg R. Hemianopic colour blindness. Э Neurol Neurosurg Psychiatry 1975; 38: 546-9.
Impaired colour vision

- achromatopsia = cannot see colour

- agnosia = loss of colour knowledge

- anomia = inability to name colour

described the association of a thrombotic state, especially a superficial migratory thrombophlebitis, with neoplasia in 1865. More recently it has been recognised that phlebitis is one of many manifestations of the coagulopathy associated with neoplasia. ${ }^{21,22}$ The cause is likely to be multifactorial, including platelet activation by the tumour cells, procoagulant production by activated macrophages, and direct tumour cell procoagulant production. ${ }^{23}$ Thrombosis is found in around $15 \%$ of all cases of malignancy, especially pancreatic carcinoma. ${ }^{24}$

Many patients with a chronic DIC will not show excessive bleeding, and diffuse thrombosis may be the only clinical manifestation. In chronic, or low grade, DIC associated with malignancy, many laboratory parameters of haemostasis may be within normal limits, or difficult to interpret. ${ }^{24,25}$ The coagulopathy may resolve with treatment of the underlying cancer, especially prostatic carcinoma. Patients with cancer may be resistant to anticoagulant therapy, with thrombotic episodes continuing, but warfarin and heparin may have some benefit on both the laboratory measures of the coagulopathy, and the clinical features. The main problem, as in this patient, may be bleeding from the tumour, and also the risk of intracerebral haemorrhage with pre-existing cerebral lesions. Aspirin and dipyridamole have been suggested as an alternative for both prophylaxis of extension of thrombi, and longterm prophylactic therapy. ${ }^{24}$ Other manifestations of the thrombotic coagulopathy seen in this patient include infarction of the kidney and spleen, digital arterial thrombosis leading to gangrene, and deep vein thrombosis with pulmonary embolism. ${ }^{26}$

14 Damasio A, Yamada T, Damasio H, Corbett J, McKee J. Central achromatopsia: behavioral, anatomic, and physio logic aspects. Neurology 1980; 30: 1064-71.

15 Heywood CA, Wilson B, Cowey A. A case study of cortica colour "blindness" with relatively intact achromatic discrimination. F Neurol Neurosurg Psychiatry 1987; 50: 22-9. 16 Kolmel HW. Pure homonymous hemiachromatopsia. Arch Psychiatr Neurol Sci 1988; 237: 237-43.

17 Ishii K, Kita Y, Nagura H, Bandoh M, Yamanouchi H. A case report of cerebral achromatopsia with bilateral occipital lesion. Rinsho Shinkeigaku 1992; 32: 293-8.

18 Green GJ, Lessell S. Acquired cerebral dyschromatopsia. Arch Ophthalmol 1977; 95: 121-8.

19 Lawden MC, Cleland PG. Achromatopsia in the aura of migraine. 7 Neurol Neurosurg Psychiatry 1993; 56: 708-9.

Symonds C Macken I Bilateral loss of vision from. cerebral infarction. Brain 1957; 80: 415-55.

21 Sack GH, Levin J, Bell WR. Trousseau's syndrome and other manifestations of chronic disseminated coagulopathy in patients with neoplasms: clinical, pathophysiologic, and in patients with neoplasms: clinical, pathophy

22 Rickles FR, Edwards RL. Activation of blood coagulation in cancer: Trousseau's syndrome revisited. Blood 1983; 62 14-31.

23 Patterson WP. Coagulation and cancer: an overview. Semin Oncol 1990; 17: 137-9.

24 Bick RL. Coagulation abnormalities in malignancy: a review. Semin Thromb Hemost 1992; 18: 353-72.

25 Graus F, Rogers LR, Posner JB. Cerebrovascular complications in patients with cancer. Medicine 1985; 64: 16-35.

26 Luzatto G, Schafer AI. The prethrombotic state in cancer. Semin Oncol 1990; 17: 147-59. 